\title{
Challenges for principled induction and mentoring of new teachers: Lessons from New Zealand and Wales
}

\author{
Frances Langdon - University of Auckland, New Zealand \\ Caroline Daly* - UCL Institute of Education, UK \\ Emmajane Milton - Cardiff University, UK \\ Ken Jones - Education consultant, UK \\ Melanie Palmer - King's College London, UK
}

\begin{abstract}
Findings from the Langdon Induction and Mentoring Survey conducted in schools employing newly qualified teachers (NOTs) in New Zealand and Wales suggest that schools should not be left to determine how they 'do' induction within national policy frameworks. The survey explored responses from key stakeholders who constitute the experiences of new teachers: head teachers, mentors, members of teaching staff and the NOTs themselves. Results suggest that conditions in schools, particularly the effects of leadership, are prime factors influencing the realization of national policy aimed at supporting NQTs. Questions are raised about how principled induction and mentoring can be achieved at scale in the context of variable, powerful school cultures. A disconnection from induction and mentoring by the majority of school staff, including leaders, is identified as a serious obstacle to be addressed.
\end{abstract}

Keywords: induction, mentoring, newly qualified teachers, NQTs

\section{Introduction}

The need to provide appropriate support and learning opportunities for newly qualified teachers (NOTs) has long been recognized (Ingersoll and Strong, 2011; FeimanNemser, 2001). Challenges on a global scale in teacher recruitment and retention have intensified international consensus about the need for sustained learning opportunities and improved conditions for new teachers, to support their needs as 'novices' and enhance the quality of their practice (Cater, 2017; Sutcher et al., 2016; OECD, 2011). The learning and development of new teachers is viewed as crucial to their efficacy and retention, and core to this is the quality of induction and mentoring. However, studies have shown the challenges of achieving effective mentoring and induction on a national scale (Hobson et al., 2009), particularly due to the complexity of multiple factors involved in developing mentoring 'toward a high-leverage practice' (Stanulis and Brondyk, 2013, 1). Adequate time and professional learning to enable mentors to support the induction of new teachers as agentive professionals is frequently underestimated (Daly and Milton, 2017). Within this context, this research examines induction and mentoring in New Zealand and Wales, two countries that have developed sustained national policy agendas to support new teachers. It asks: What do the perceptions of school leaders, school leaders who are mentors, other mentors, teaching staff 
and NQTs reveal about the challenges and opportunities for establishing principled induction and mentoring in schools? In times of increasing policy intervention around the entitlements of new teachers, we examine challenges for how principled induction and mentoring can be achieved at scale in the context of variable, powerful school cultures. Harnessing the professional capital within schools has been argued to be essential to optimizing the learning potential of a school for both its teachers and pupils (Hargreaves and Fullan, 2012). This relies on conditions that enable all members of school communities to benefit from their collective knowledge and experience, to forge new insights and practices. Our analysis suggests however that there is a disconnection of the majority of staff in a school (including leaders) from induction and mentoring, which needs to be addressed in order to achieve policy goals and optimize learning conditions for new teachers.

\section{Principled induction and mentoring}

The distinction between induction and mentoring needs to be clarified to avoid what Langdon et al. (2014) have criticized as the 'conceptual confounding' of the two. These are not interchangeable terms and their confusion is damaging to understanding the 'multifaceted nature' of induction systems:

Induction has been defined as the entire system of policy, resources, professional development opportunities, guidance, and support provided to anyone starting in a new role, in this case NOTs (Ingersoll \& Strong, 2011), whereas mentoring more precisely relates to guidance and support provided by one or more experienced colleagues to the new teacher. So defined, mentoring is a component of induction (Bullough, 2012). (Langdon et al., 2014, 93)

An extensive review of literature conducted by Langdon et al. (2012) identified twelve principles underpinning effective induction and mentoring, linked to three core 'assumptions' that characterize the learning and development of new teachers. The first assumption is that, at national policy level, there is a commitment to the professional learning of new teachers and related resourcing. Second, leadership has a significant impact on the effective realization of policy within school cultures for the induction and mentoring of new teachers. School cultures are greatly influenced by leaders, who have long been recognized as catalysts in mediating and shaping the enactment of national policy. Third, mentors are capable of mentoring in that they are able to engage in co-constructive enquiry-based mentoring activities, termed as 'educative'. This does not suggest that a uniform 'practice' of mentoring is desirable. Rather, educative mentoring of new teachers comprises numerous practices. What links them is that they support mentors' own learning and the collection of evidence of their engagement with enquiry, which are viewed as essential to the achievement of rich goals for mentoring within school learning communities.

The principles, outlined in Table 1, go beyond 'survival' and enculturation into particular school environments (Britton et al., 2003), and instead relate to long-term learning goals for new teachers. They support educative goals for teachers' learning, based on an enquiry orientation that can develop practice for both mentors and mentees, supported by national policy and resource. They indicate a shift away from what Stanulis and Brondyk (2013) have called 'buddy' mentoring and emphasize teacher learning as an enquiry practice that is achieved through mutual endeavour between mentor and mentee (Norman and Feiman-Nemser, 2005; Langdon and Ward, 2015). 
Mentors undertake a role as teacher-educator, going beyond passing on advice about practical teaching as a more experienced 'expert'. The mentor is positioned as a colearner who is able to co-construct knowledge and understanding about teaching that can lead to the development of altered beliefs and practices for both mentor and mentee about pupils' learning and about the role of the teacher.

\section{Table 1. Twelve principles for induction and mentoring}

\begin{tabular}{|c|c|}
\hline 1 & $\begin{array}{l}\text { There is coordination at the national, state, or regional levels with regard to the policies } \\
\text { and standards for induction and mentoring programs and for resource allocations } \\
\text { associated with those programs. }\end{array}$ \\
\hline 2 & $\begin{array}{l}\text { The assessment standards and policy guidelines for induction and mentoring and the } \\
\text { expectations associated with each are consistently and effectively communicated. }\end{array}$ \\
\hline 3 & There are standards that guide the evaluation of NQTs. \\
\hline 4 & $\begin{array}{l}\text { Career-long learning and development is promoted by coordination between pre- } \\
\text { service teacher education, induction and mentoring programs, and continuing } \\
\text { professional development opportunities. }\end{array}$ \\
\hline 5 & Effective leadership is foundational to NQTs' induction. \\
\hline 6 & Models of quality teaching are present and observed within the school environment. \\
\hline 7 & Work conditions are adapted to the NQT's novice status. \\
\hline 8 & Collaborative and collegial school cultures support NQT learning and development. \\
\hline 9 & $\begin{array}{l}\text { Mentors in the school-based induction and mentoring program are willing and } \\
\text { prepared to support the learning and development of NQTs. }\end{array}$ \\
\hline 10 & $\begin{array}{l}\text { NQTs' professional identity and their beliefs about learning and teaching are } \\
\text { influenced by the experiences within and culture of the school environment. }\end{array}$ \\
\hline 11 & $\begin{array}{l}\text { NQTs are encouraged to make pedagogical and professional choices and to act on } \\
\text { those choices as a means of building their sense of efficacy. }\end{array}$ \\
\hline 12 & $\begin{array}{l}\text { Because learning is always situated, the classroom becomes the primary site for the } \\
\text { learning and development of both NQTs and their students. }\end{array}$ \\
\hline
\end{tabular}

Source: Langdon et al., 2012, 401.

Such principles indicate aspirational goals for mentoring that resist survivalist discourses and narrow perceptions of how to retain teachers based on easing the path into established routines. Talbot et al. (2018) have cautioned that educative mentoring that is transformational of learning and teaching for all those involved requires sufficient space and time to develop a 'complex set of pedagogical tools' that can support an enquiry stance, including critical reading of research, self-auditing and the development of 'dialogic mentoring' (51). Peiser et al. (2018), in exploring the challenges of realizing principled goals for mentoring set out by national policy frameworks, suggest that the challenge for teachers to learn is greater than in other professions - teaching, they argue, relies on a less clearly defined body of knowledge, in which the links between practical and theoretical knowledge are 'more tenuous' (10). Professional knowledge for teachers is subject to 'alternative logics' (Hordern, 2016) that are influenced by policymaking and personal beliefs and, crucially, the shared practices within schools that help determine what is relevant for teachers to know and do. The realization of educative mentoring goals based on principles of enquiry, collegiality and mutually constructed learning may therefore be elusive even where there is relatively generous resourcing and policy support. 


\section{The complexity of schools}

The complexity of schools is indicated in the principles (Table 1) quoted from Langdon et al. (2012). National, regional and local education policymaking help to shape the conditions within schools for new teachers to learn effectively (European Commission, 2015). Godfrey and Brown (2018) have conceptualized schools as acting within wider ecologies, in which forms of collaboration within and between schools are related to external stakeholders such as local authorities or universities who can support the mobilization and orchestration of diverse resources. Policy, linked to resource, influences extensively what is enacted as induction and mentoring by members of a school community and thus the relational aspects of induction and mentoring are affected by factors outside as well as within the school.

Interactions between individuals therefore take place within conditions that are constituted by the school system, classrooms, external players and the policy environment, which together shape values, understandings and practices, and inform the dialogue that takes place among stakeholders. From a socio-cultural perspective, numerous studies have indicated that school contexts impact extensively on the interactions among stakeholders, enacted through what Wenger $(1998,162)$ termed 'relations of practice'. These interactions effectively constitute the learning and development of all members of school communities, a theoretical perspective that informs extensive research into teachers' professional learning (for example, Cordingley, 2008; Flores and Day, 2006).

These dynamic relations create the potential for inconsistencies between policymaking and implementation, identified by Jones (2011) as 'the inability of policy-makers to reach as far as the operational level of education - schools and their classrooms' (760). Individual school contexts create variability and can have a major impact on the quality of induction and mentoring (Bubb and Earley, 2007). It has been argued that this is especially because school leaders exert considerable influence on schools as sites of professional learning, influencing the interactions that take place, both overtly and covertly (Timperley et al., 2008). They shape the conditions that mediate the organizational culture of the school, the interpretation and implementation of policy and how the needs of new teachers are addressed, including 'how new teachers are met and how their knowledge is valued and asked for' (Sunde and Ulvik, 2014, 94). In essence, within the wider ecologies that influence school cultures, the school leader is vital to the relations that contribute to induction and mentoring.

Schools thus provide complex environments for the learning and development of new teachers. As multidimensional systems, it is argued by Wenger et al. (2002) that schools reflect the affordances of communities of practice, by which they are dynamic and constantly evolving, constructed by their participants' interactions in contexts of internal and external policy change. These are the conditions in which induction and mentoring take place and in which the realization of educative mentoring becomes possible but is by no means a necessary consequence. School communities of practice are 'individual, multifaceted and relational' (Langdon, 2017, 1) and comprise interactions that are non-linear (between mentor, teacher, other teachers etc.) and multi-layered (interactions between the school system, individuals, classrooms, the community and the policy environment). Critics of the professional learning potential of school communities (Reeves et al., 2005) argue that there is insufficient attention to the micropolitical experiences of teachers. These can validate and perpetuate the status quo of relations and maintain restricted learning opportunities within organizations. 


\section{Context}

The study explores the challenges of achieving principled induction and mentoring, based on the perceptions of key stakeholders in small systems that share geopolitical conditions regarding the retention of teachers alongside wider educational reform agendas. These systems act as bounded sites for nation-wide, high-stakes initiatives directed towards supporting new teachers. New Zealand and Wales, serving populations of 4 million and 3.1 million respectively, are small education systems that have developed policy focused on the entitlement of NQTs to professional learning that meets national guidelines, ensuring mentoring for all new teachers and increasing the obligations of stakeholders at local and national levels to provide specified conditions that support their professional growth throughout a period of mandatory induction (New Zealand Teachers Council, 2011; New Zealand Education Council 2015; National Assembly for Wales, 2003; Welsh Government, 2017b).

It is in this context that the Langdon Induction and Mentoring Survey (LIMS) was developed in New Zealand (Langdon et al., 2012). Three iterations of the survey were conducted in 2012-2014 in schools employing NQTs, which explored perceptions of mentoring and induction held by head teachers, mentors, members of teaching staff and the NQTs themselves. A revised 56 -item survey was reported on by Langdon et al. in 2014 and this version was adapted to the Welsh context and deployed in 2016. Quantitative analysis of the New Zealand findings was reported as a single-country study (Langdon et al. 2014) and the Welsh survey has been analysed in the context of current Welsh policymaking (Milton et al., forthcoming). This paper builds on these studies by providing an analytical overview of the main outcomes from both surveys and identifies where the Welsh data provides further insights into the key features of induction and mentoring previously identified in New Zealand, aiming to illuminate where the data contrasts with or adds weight to the previous conclusions.

\section{New Zealand}

Newly qualified teachers in New Zealand have a two-year period of induction (longer than the majority of education systems) during which they are provisionally certificated. The teacher receives an in-school mentor who supports their practice development and the collection of evidence to meet the criteria for full registration. During induction the new teacher has a reduced teaching allocation and mentors receive a supplementary allowance. Schools receive funding from the Ministry of Education throughout the induction period and guidelines support them in carrying out their obligations. Resource is also intended to enable mentors to attend a programme of professional learning. At the end of two years, new teachers must meet national criteria to become fully certificated (New Zealand Teachers Council, 2010).

\section{Wales}

Wales has a year-long period of statutory induction, during which NQTs are entitled to a reduced teaching allocation with funding support from the Welsh Government. They collect evidence throughout the year to demonstrate that they meet the Professional Standards for Teaching and Leadership (Welsh Government, 2017a). NQTs are allocated an in-school induction mentor and receive periodic support from an external verifier, normally provided by a Local Authority acting as the 'appropriate body' that can confirm the successful completion of induction. From 2012 to 2015 NQTs were 
also entitled to support from an external mentor for three years if they engaged in a national master's programme aimed at developing their professional practice.

\section{Methodology}

The LIMS (Langdon et al., 2012) was developed in New Zealand to provide a theoretically derived, psychometrically sound measure of the quality of mentoring and induction in schools. The survey is conducted nationally online with participants in schools employing NQTs. It was applied to Welsh schools in 2016, following adaption to reflect terminology and policy within the Welsh education system. Maximum fidelity with the original LIMS design was maintained. Perceptions of induction and mentoring are surveyed by individual factors (gender, number of years teaching, type of initial teacher education, teaching discipline, position held in school, time taken to complete induction), school factors (school type, language medium, roll size), and contextual factors (the socioeconomic status of the school, its size and region). Evidence from New Zealand (ibid.) concluded that the LIMS yields valid and reliable data that provides a measure of how participants perceive induction and mentoring within a theoretical framework based on the twelve principles shown in Table 1. A factor analysis of the adapted Welsh survey items indicated that the LIMS appeared to have a similar factor structure to responses from participants in New Zealand. Factor analysis forms the basis for the quantitative survey design and the methodology does not include open text questions. Its intention is to provide statistical results that form the basis for analysis that is informed by the literature. It is acknowledged that a future iteration of the survey would benefit from qualitative open-ended survey items that would bring a further dimension to the analysis. For a detailed technical account of the development of the survey and the New Zealand studies see Langdon et al. $(2012,2014)$.

Survey items were developed, which are precisely linked to the twelve principles (Langdon et al., 2012). There are four or five survey items for each principle, which are presented as statements for participants to consider, each one beginning 'in my school ...', for example 'in my school newly qualified teachers are listened to by other teachers'. Respondents were asked to indicate the extent of their agreement with the statements. Mean LIMS scores (M) out of one hundred were calculated on the basis of these responses, and reported by individual, school or contextual factors, for instance by gender or role in school. These scores provide the basis for the analysis of stakeholders' perceptions.

\section{Sample}

\section{New Zealand}

The survey was completed by 696 participants. A large proportion of the participants were female (71.1 per cent; male: 28.9 per cent). The majority of the participants selfidentified as being of a New Zealand Pakeha/European ethnic background (76.9 per cent). Respondents worked in schools throughout New Zealand, primarily in urban areas (74.4 per cent; rural: 25.6 per cent). Those who had never worked in another school totalled 17.8 per cent, and the same figure had worked in one school previously, while 10.8 per cent had worked in two schools and 53.7 per cent had worked in more than two schools. All participants taught in English-medium schools. 


\section{Wales}

The survey in Wales was completed by 99 participants. As in New Zealand, a large proportion of the sample were female (68.8 per cent; male: 31.2 per cent). The majority of the participants self-identified as being of a White ethnic background (97.9 per cent). Respondents primarily worked in schools in urban areas (69.8 per cent; rural: 30.2 per cent), all over Wales. Those who had never been employed in another school numbered 20.6 per cent, compared to 34 per cent who had been employed in one other school, 16.5 per cent in two other schools and 28.9 per cent in more than two. Most were teaching in schools which taught in English (78.6 per cent), with the remainder being bilingual schools or teaching in Welsh.

Both samples are representative of dominant female gender and ethnicity in their teaching populations and their geographical region, and represent a distribution of socio-economic status (SES) categories of school. The larger New Zealand sample may have been influenced by the fact that mentors receive a supplementary allowance for their role. Schools employing NQTs were identified by the New Zealand Ministry of Education for the survey to be sent directly to them, whereas this information is protected in Wales so schools were contacted via a less personalized process. The small sample for Welsh participants is acknowledged and means that we exercise caution in making claims based on the results; direct comparative analysis is not the aim of this study. We synthesize results from both studies and explore where the Welsh data provides significant support for hypotheses that emerged from the earlier work in New Zealand.

\section{Findings and analysis}

Four dominant factors emerge that illuminate the challenges and opportunities for principled induction and mentoring in schools: the divergence of perception between school leaders, school leaders who are mentors, and other participants; the relatively unfavourable impressions of induction and mentoring held by teaching staff members; the effects of teaching in more than one school; mentors' access to professional development. The lack of impact of a school's socio-economic status on perceptions of induction and mentoring is also discussed.

There was no significant impact on perceptions across stakeholders in either survey in terms of gender or the length of time employed in current school. Perhaps surprisingly, mentor-related items also made no significant impact on perceptions except in relation to having access to professional development. Results from the surveys indicate that overall, in participating schools in New Zealand and Wales, schools leaders', teachers', mentors' and NQTs' perceptions of the quality of schools' comprehensive induction and mentoring programmes are relatively high. The mean LIMS scores are shown in Table 2.

Table 2. Mean Total LIMS Scores by Position for New Zealand and Wales Participants

\begin{tabular}{lll}
\hline Role & New Zealand score /100 & Wales score /100 \\
\hline School leader & 88.97 & 86.17 \\
School leader and mentor & 87.12 & 85.80 \\
Mentor & 80.12 & 80.60 \\
Teaching staff member & 73.94 & 64.92 \\
Newly qualified teacher & 80.37 & 76.82 \\
\hline
\end{tabular}




\section{Divergence of perception between leaders and other participants}

Although the overall LIMS scores are positive, three features indicate the challenges of achieving induction and mentoring that is coherent and cohesive for all school members:

i. in both countries, school leaders and those occupying combined school leader and mentor roles had more positive perceptions than all other stakeholders;

ii. teaching staff members in both countries had the least favourable impressions of induction and mentoring. In Wales this difference was particularly acute, with a mean score of 64.92 compared with Welsh school leaders at 86.17, school leaders/ mentors at 85.80 and mentors at 80.60 . NQTs in Wales reported less positive perceptions (76.82) than their school leaders, leaders/mentors, and mentors, but their perceptions were not as negative as other teaching staff members;

iii. there is a considerable gap between NQTs' and school leaders' perceptions in both data sets.

Although the differential in the New Zealand data was less pronounced, Langdon et al. (2014) have commented on the 'exceptionally positive views' (99) of school leaders that manifested consistently across regions, school sectors and socioeconomic levels. The differential in both countries between the leaders' perceptions and those of other stakeholders - including mentors who are not school leaders - is consistent with studies that suggest school leaders are unlikely to have deep knowledge of how induction and mentoring is being realized in their schools. 'Conflicts of interest' were identified by Brady (1999) as responsible for a 'mismatch' between school leaders' and NQTs' perspectives on the developmental needs of new teachers. The argument is that leaders prioritize indicators that their schools are successful organizations in 'global' and 'general' terms and are not well-informed about the day-to-day experiences of new teachers. It is reasonable that those who are ultimately accountable for provision, including allocating the use of dedicated resources, perceive they are carrying out their obligations correctly. The perceptual distance from the NQTs themselves however is disconcerting and reflects a 'lack of awareness' on the part of school leaders that has been identified by Sunde and Ulvik $(2014,294)$. They attribute 'lack of awareness' of NOTs' perspectives to the tendencies of some leaders to view managerial efficiency as an indicator of effective induction and mentoring, citing leaders who wanted new teachers to learn 'the way we do it in our school'. Such leaders judged effective support in terms of the seniority and teaching experience of the mentors they nominated, prioritizing new teachers' socialization into the workplace over 'supportive, emotional and professional dimensions' (ibid.).

In turn, lack of awareness of senior leaders may partly result from NQTs' desires to maintain strategic silence about difficulties they experience, due to fears of being judged in a context where being able to perform 'business as usual' is imperative and the power-differential between players in the induction process is pronounced (Hobson and Malderez, 2013; Hobson and Mclntyre, 2013). The gap between leaders' and NQTs' perceptions in the surveys is a concern. It suggests a barrier to effective induction and mentoring that needs to be overcome within reconfigured learning relations within schools. This has been identified by Killeavy (2006) who suggested that induction should be reconceptualized to encompass school leaders who develop shared engagement with NQTs in enquiry-oriented professional learning - a radical revision of learning relations in many schools. 


\section{The relatively negative perceptions of induction and mentoring held by teaching staff members}

There was a marked difference in perceptions between teaching staff members and all other participants, raising questions about the realization of school learning communities that can support induction and mentoring. Teaching staff members had the lowest mean scores of all participants, 73.94 in New Zealand and just 64.92 in Wales. There is a clear indication of a disconnection between those who play an explicit role in induction and mentoring and members of the school community who do not. It indicates that 'relational school communities of practice' are not necessarily collaborative and can reinforce bounded professional learning among members, lacking perceived relevance or shared investment for those occupying separated roles within school cultures. The results indicate school cultures where the 'relations of practice' constitute induction and mentoring as discrete entities, disassociated from the pedagogical development of all staff. This raises questions about the work to be done not only to develop ambitious policy for induction and mentoring as educative, but to support its enactment so that all stakeholders can develop shared understandings and values within schools as sites of professional learning.

\section{The effects of teaching in more than one school}

In Wales, participants who had been employed in more than two schools had the least positive views of induction and mentoring, whereas those employed in just one school were the most positive. In New Zealand the reverse was true: those who had been employed in more than two schools had the most positive perceptions and those employed in only one school had the least. Consideration of the literature and specific national contexts helps to illuminate this contrast. The benefits of multiple experiences and altered perspectives brought about by moving between contexts for professional learning have been identified in workplace literature. 'Expansive' environments (Hodkinson, 2009) encourage exposure to different workplaces, enabling individuals to develop an enquiry orientation that can disrupt previously held beliefs and assumptions. The New Zealand participants may reflect the positive effects of having experience of more than one school. 'Boundary-crossing' (ibid. 165) in terms of concurrent access to other schools' cultures is limited for most teachers, but working in more than two schools - albeit serially - accumulates exposure to diverse practices, people or objects from differing contexts to achieve a form of hybridity (Engeström et al., 1995). This can help to challenge assumptions and prevailing beliefs that characterise individual organizations. It is not surprising that the New Zealand sample represented stakeholders whose perceptions of induction and mentoring may have benefitted from exposure to more than one school.

That is different however from exposure to unstable employment patterns as a NQT, which is a long-term characteristic of the Welsh education system (National Assembly for Wales, 2015), partly due to an over-supply of NOTs graduating from programmes of initial teacher preparation (in 2015 over 80 per cent of NQTs in Wales were on temporary or supply-teaching contracts with insecure access to mandatory induction). High rates of NOT temporary employment also feature in New Zealand, with only some 15 per cent of entrants being on permanent contracts in 2015 (New Zealand Post Primary Teachers' Association, 2016). The situations are not entirely comparable however - relatively high mobility in-year is a particular feature of the Welsh system. In NewZealand the (unofficial) 'trial' basis of NOT temporary employment may not have the same impact in-year on access to induction. In Wales, the over-supply of new teachers 
contributes to NQTs moving schools in-year to find further work, including periods of supply teaching. There are therefore subtle contrasts in NQTs' access to sustained induction and mentoring in both countries although they share being vulnerable to temporary employment. This is an area that warrants further investigation to identify varying impacts of employment patterns on experiences of induction and mentoring and long-term perceptions of stakeholders. High NOT mobility, which disrupts the first terms of teaching, is most likely to have enduring impact on stakeholders' perceptions. The importance of stable employment contexts, enabling sustained and coherent induction and mentoring, cannot be disassociated from policy that aims to assure the entitlements and obligations of an induction system.

\section{Mentors' access to professional development}

There were no significant impacts on mentors' perceptions of induction and mentoring by the length of time mentoring, current number of mentees or the frequency of meetings with mentees. These factors relate to the amount of experience that mentors bring to their perceptions of induction and mentoring, and this suggests that being 'experienced' is complex. Daly and Milton (2017) argue that experience is not primarily related to how much mentoring has been undertaken, but rather to transformed mentoring practice brought about by high-quality professional development that challenges hierarchical views of expertise and harnesses diversity within mentoring communities. In both surveys, mentors with access to professional development scored very positively, with a consistent differential from mentors without access to professional development. Mentors' mean LIMS scores (M) and Standard Deviation (SD) are illustrated in Table 3 in relation to access to professional development.

Table 3. Mentor access to professional development

\begin{tabular}{lllllllll}
\hline & \multicolumn{7}{l}{ New Zealand } & \multicolumn{7}{c}{ Wales } \\
\cline { 2 - 9 } $\begin{array}{l}\text { Access to } \\
\text { professional } \\
\text { development }\end{array}$ & $\%$ & $n$ & $M$ & SD & $\%$ & $n$ & $M$ & SD \\
\hline Yes & 71.6 & 121 & 84.66 & 13.19 & 79.6 & 43 & 84.56 & 9.02 \\
No & 28.4 & 48 & 79.82 & 10.48 & 20.4 & 11 & 79.79 & 15.11 \\
\hline
\end{tabular}

The mean LIMS scores for those with access to professional development was 84.66 in New Zealand and 84.56 in Wales; contrasting scores for those without access was 79.82 in New Zealand and 79.79 in Wales. The Welsh survey adds weight to Langdon et al.'s (2014) analysis that there is a strong correlation between access to relevant professional development and engagement with principled induction and mentoring by mentors. The significant minority of mentors who did not have access to professional development illustrates that this is not an entitlement or requirement in either system, despite mandatory mentoring of NQTs in both countries and detailed guidelines for mentor professional development in New Zealand. Numerous studies have found that mentors are frequently inadequately prepared to fulfil the complex demands of the role and there is a relatively small research base in mentors' professional development in induction contexts (Ingersoll and Strong, 2011; Jones, 2009). This study suggests the need for more coherent policymaking to make professional development mandatory, and linked to resource allocation for this important component of induction. 
This is of further relevance when looking at the results for the impact of volunteering to mentor. Overall LIMS scores for mentors who volunteered for the role are similarly positive at 84.80 in New Zealand and 83.41 in Wales, as might be reasonably expected. In Wales however, there was little difference in perceptions of induction and mentoring between those who volunteered to mentor and those who did not (83.86). By contrast, in New Zealand, those who did not volunteer to mentor had less positive perceptions (79.46) (Table 4).

Table 4. Mentor volunteers and non-volunteers

\begin{tabular}{lllllllll}
\hline & \multicolumn{7}{l}{ New Zealand } & \multicolumn{7}{c}{ Wales } \\
\cline { 2 - 9 } Mentors & $\%$ & $n$ & $M$ & SD & $\%$ & $n$ & $M$ & $S D$ \\
\hline Volunteer & 71.6 & 121 & 84.80 & 12.44 & 61.1 & 33 & 83.41 & 11.50 \\
Non-volunteer & 28.4 & 48 & 79.46 & 12.47 & 38.9 & 21 & 83.86 & 12.36 \\
\hline
\end{tabular}

The impact on teachers' practice of 'volunteering' in professional contexts needs to be problematized. Timperley et al. (2008) suggest that in professional learning contexts, volunteering is an unreliable indicator of future changes in practice that enhance learner outcomes. More important is the level of engagement in learning over time once a commitment to a professional learning experience is undertaken. Sustained engagement with the mentoring role and related professional development may counter initial lack of motivation for some. Mentors in both countries with access to professional development had comparable high mean LIMS scores (84.66 for New Zealand and 84.56 for Wales) but a greater proportion of mentors in the Welsh survey had access to professional development, at 79.6 per cent compared with 71.6 per cent in New Zealand. It is reasonable to conclude that it matters more for mentors to access professional development than that they volunteer.

There are implications for national initiatives that seek to provide entitlement to mentoring for NQTs throughout induction, for example in England where current proposals are to extend mandatory mentoring of NQTs over a two year period (DfE, 2018). Not volunteering to mentor does not equate with reluctance to learn - and this matters where the provision of sufficient 'volunteer' mentors over two years on a national scale may be challenging. The picture that emerges from both surveys is that access to professional development positively affects mentors' perceptions of induction and mentoring. This is an important message for systems developing mentor roles where there is currently very patchy, non-mandatory or under-resourced provision for mentor learning and development.

\section{School socio-economic status (SES)}

Similar proportions of respondents in both countries worked in low, medium and high SES school contexts, calculated using national decile ratings in New Zealand (a measure of the socio-economic position of a school's student community relative to other schools throughout the country) and free school meal (FSM) indicators in Wales. Most respondents worked in mid-SES schools, 44 per cent in New Zealand and 46 per cent in Wales. The fewest respondents worked in low-SES schools, 24 per cent in New Zealand and 24 per cent in Wales. In New Zealand, 32 per cent worked in high-SES schools compared to 30 per cent in Wales. School SES status did not emerge as a factor impacting on overall perceptions in either survey. Langdon et al. (2014) 
reported that this lack of effect in the New Zealand data is atypical and contrasts with other findings (e.g. Ingersoll and Strong, 2011), which suggested that local social and economic disadvantage impacts negatively on the capacities of schools as contexts for professional learning. The analysis hypothesized that national funding in New Zealand to support schools with low SES may have a significant impact on conditions that increase the overall perceptions of stakeholders and account for the lack of SES as a factor. Schools serving disadvantaged communities receive more funding. This contrasts with dominant patterns in other nations where local revenues impact directly on the funding available for professional learning and development, restricting opportunities in poorer areas. Wales has also pursued a policy of national funding for induction and mentoring and, like New Zealand, there was no significant difference in overall perceptions by region or by SES. The Welsh data add weight to the hypothesis that policy for induction and mentoring that is nationally applied and resourced, with ring-fenced funding according to a standard formula, contributes to positive perceptions overall in schools serving pupils living in disadvantaged circumstances. There are significant implications for the realization of wider socially just goals related to the induction and mentoring of new teachers on a national scale.

\section{Discussion}

Mandatory requirements can reasonably be argued to reduce unequal experiences for NQTs and help to counter the potential for guidelines to be neglected and/or the effect of localized financial under-investment in induction and mentoring. The crucial issue is that policy needs to be ambitious, based on informed understandings of the multi-faceted nature of induction and its complexity. Insufficient attention to core components - sustained, mandatory professional development for mentors; whole-staff engagement in collaborative professional learning; boundary-crossing that exposes all stakeholders to multiple and external perspectives; stable employment conditions for NQTs - is likely to result in enactment of policy that lends itself to 'pragmatic alternatives' ( $O$ 'Brien and Jones, 2005). For induction and mentoring, these alternatives aim to ensure 'coping' on a day-to-day basis and help assimilate new teachers into existing school cultures, but help maintain restricted goals for induction and mentoring. Managerial discourses can dominate school leaders' understandings of induction and mentoring (Sunde and Ulvik, 2014) and account for their highly positive views that differ from those of NQTs and the rest of the staff. We do not subscribe to criticism of leaders - their roles are excessively pressurized and in Wales recent research (Connolly et al., 2018) has identified problems in attracting individuals to the role.

Achieving principled mentoring and induction involves addressing multiple factors. Policymaking that looks at factors in isolation and directs resources towards pragmatic solutions does not address the issues that have been identified (as for example in England, where recent policy around the employment and mentoring of NQTs is geared towards providing a content-focused 'framework' for new teachers to follow, concentrating support on certain geographical regions, certain routes into teaching, certain subjects, certain demographics of teachers). This lends itself to competing priorities and diverts attention away from the substantive issues identified in the LIMS surveys as having a consistent impact on induction and mentoring.

The greatest challenge is for policy to lend support to leaders, encouraging them to harness the 'professional capital' within complex school cultures: learning within a community, fostering an enquiry perspective for teachers' as well as pupils' 
learning, and achieving genuinely dialogic discourse among professionals within and beyond 'mentoring' relationships. This suggests a considerable shift away from the performative agendas that have dominated school development plans, spending and teachers' access to professional learning for two decades in countries like New Zealand and Wales (along with the rest of the UK). Hardy (2008) found that policy tensions ultimately 'militated against policy support for more context-specific, long-term, enquiry-based, collaborative professional development practices' (ibid. 103). Policy tensions have significant effects on competing priorities for the mentoring and induction of new teachers in performative school environments, which influence choices about what to focus on within mentoring resources. Community does not necessarily imply shared practice (Wenger, 1998) and membership of multiple groups can mean having to resolve 'ambivalent relations' (ibid., 109) between the plural communities in which stakeholders participate. This study has highlighted the disassociation of teaching staff members - who form the majority of those working in schools - from induction and mentoring. Their less positive LIMS scores do not necessarily indicate a more negative viewpoint as such. Teaching staff perceptions of 'my school' reflect how they are shaped by multiple relations that contribute to what they believe deserves attention. It is possible to conjecture that teaching staff demonstrate a lack of perceived relevance of induction and mentoring to their current priorities; they may have exercised caution in offering affirmative views of induction and mentoring, due to feeling that this does not involve them or they simply 'don't know' enough to answer questions with conviction. Whatever the reasons for the apparent disconnection between general teaching staff and other stakeholders, there appears to be insufficient investment in the professional capital that exists and that can be produced together through having NQTs in a school.

The challenges of achieving principled induction and mentoring at scale are therefore considerable. Jones's (2011) analysis of the obstacles to policy 'reaching' schools and classrooms warned about the pervasiveness of 'pragmatic alternatives'. Policies can only structure and standardize induction and mentoring procedures (Killeavy, 2006). It is leadership that predominantly shapes school cultures that can foster induction, and mentoring practices where 'everyone is expected to learn' (ibid., 174). This is far harder to realize. For induction and mentoring policy development to have a positive impact it needs to be premised on all stakeholders in the school community being learners - including leaders. Expectations need to be explicit, aimed at harnessing the capacity of all to participate on a range of formal and informal levels. This means encouraging leaders to help others to resist restricted understandings of induction and mentoring centred on a privatized practice that takes place between mentor and mentee.

'De-privatising of practice' (MacBeath 2012, 70) with regard to induction and mentoring would be an appropriate goal to embed teachers' professional learning within the school community. Individual schools should not be left to decide how to 'do' induction and mentoring on a basis of complying with policy frameworks. Professional development for mentors needs to be mandatory and to support access to external perspectives. Leaders too need supportive professional learning to lead change in schools and to re-orient their perceptions of themselves as learners alongside their NOTs and mentors. A separate 'curriculum' that increases privatized practices of induction and mentoring for NQTs is not a valid way forward for countries seeking to develop coherent policy that relates induction and mentoring to wider ambitions for what schools can achieve. The relationship between national policy, school contexts and leadership is highly complex; it requires the reduction of pressures on schools 
brought about by policy agendas that are antithetical to or distracting from a sustained investment in teachers (all teachers) learning within school communities.

\section{Conclusion}

There are clear differences in perceptions of induction and mentoring between leaders, NOTs, and particularly teaching staff that demand attention. These differences dominated the data in our study, suggesting that induction and mentoring remain privatized practices between mentor and mentee in many of the participating schools. The collective learning resource that is constituted by all members of a school community appears to be underutilized. Future research is needed into the disconnection from induction and mentoring of most members of school communities - including leaders. This includes a need to explore the ways in which role definitions and becoming 'experienced' militate against the expectation that staff invest in the learning of new teachers and how leaders influence such expectations. Such research is needed urgently to prevent pragmatic policymaking that addresses induction and mentoring as discrete entities that are developed and managed separately from attention to school cultures.

\section{Notes on the contributors}

Frances Langdon is an Honorary Senior Academic at the University of Auckland, where she led the School of Learning Development and Professional Development from 2006 to 2011. Her research and teaching is in the field of professional learning and development with a particular interest in early career learning, induction and mentoring, and the development of professional expertise. She was the principal investigator of the NZTC National Primary and Intermediate Induction and Mentoring Pilot (2009-11), and the Leading Learning in Induction and Mentoring project (2012-18).

Caroline Daly is a Reader in Education at the UCL Institute of Education and Associate Professor at the University of South Wales. She has worked extensively in the field of professional learning for Early Career Teachers. Her research and development work is in mentoring Early Career Teachers, professional learning and the school factors that affect the learning of new teachers. She is a Fellow of the International Professional Development Association.

Emmajane Milton is a Reader in Education at the School of Social Science, University of Cardiff. She has worked in education for 19 years in a wide range of senior leadership roles within academia, policy development and the statutory school sector. She is a National Teaching Fellow of the Higher Education Academy and her research interests are focused around professional learning, educative mentoring and the recruitment and retention of education professionals.

Ken Jones taught in schools in London before returning to Wales to work in higher education. He worked as Head of Education, Dean of Humanities and Senior Consultant for Professional Learning, and is an Emeritus Professor at the University of Wales Trinity Saint David. He has worked internationally, specializing in the fields of school leadership and professional learning. He has been president of the International Professional Development Association (IPDA) and is Managing Editor of Professional Development Education. 
Melanie Palmer is an Honorary Research Fellow at the University of Auckland. Her research interests focus on child and adolescent development and the multiple factors that influence development. She is particularly interested in supporting those involved in the care and education of children and developing high-quality evidence for supportive interventions. She has experience in quantitative and qualitative methodologies.

\section{References}

Brady, M. (1999) The Induction of Newly Qualified Teachers: Perceptions of the professional development of NQTs as described by new teachers, their mentors and headteachers. Paper presented at the British Education Research Association annual conference, University of Sussex, 2-5 September.

Britton, E., Paine, L., Pimm, D. and Raizen, S. (2003) Comprehensive Teacher Induction Systems for Early Career Learning. Dordrecht: Kluwer.

Bubb, S. and Earley, P. (2007) Leading and Managing Continuing Professional Development. 2nd edition. London: Paul Chapman.

Bullough, R.V. (2012) 'Mentoring and new teacher induction in the United States: A review and analysis of current practices'. Mentoring and Tutoring: Partnership in Learning, 20 (1), 57-74.

Cater, J. (2017) Whither Teacher Education and Training? Higher Education Policy Institute, HEPI Report 95. Oxford: Higher Education Policy Institute.

Connolly, M., Milton, E., Davies, A. and Barrance, R. (2018) Turning Heads: The impact of political reform on the professional role, identity and recruitment of head teachers in Wales'. British Educational Research Journal, 44 (4), 608-25.

Cordingley, P. (2008) GTC Qualitative Study of School-level Strategies for Teachers' CPD. Coventry: Centre for the Use of Research \& Evidence in Education (CUREE).

Daly, C. and Milton, E. (2017) 'External mentoring for new teachers: Mentor learning for a change agenda'. International Journal of Mentoring and Coaching in Education, 6 (3), 178-95.

Department for Education (DfE) (2018) Strengthening Qualified Teacher Status and Improving Career Progression for Teachers: Government consultation response. Online. www.parliament. uk/business/publications/written-questions-answers-statements/written-statement/ Commons/2018-05-08/HCWS669 (access 30 August 2018).

Engeström, Y., Engeström, R. and Kärkkäinen, M. (1995) 'Polycontextuality and boundary crossing in expert cognition: Learning and problem solving in complex work activities'. Learning and Instruction, 5 (4), 319-36.

European Commission (2015) Education \& Training 2020: Shaping career-long perspectives on teaching. A guide on policies to improve Initial Teacher Education. Luxembourg: Publications Office of the European Union. Online. https://tinyurl.com/y6qtuefy (accessed 15 March 2018).

Feiman-Nemser, S. (2001) 'From preparation to practice: Designing a continuum to strengthen and sustain teaching.' Teachers College Record, 103 (6), 1013-55.

Flores, M., and Day, C. (2006) 'Contexts which shape and reshape new teachers' identities: A multiperspective study'. Teacher and Teacher Education, 22, 219-32.

Godfrey, D. and Brown, C. (2018) 'How effective is the research and development ecosystem for England's schools?' London Review of Education, 16 (1) 137-53.

Hardy, I. (2008) 'The impact of policy upon practice: An Australian study of teachers' professional development'. Teacher Development, 12 (2), 103-14.

Hargreaves, A. and Fullan, M. (2012) Professional Capital: Transforming teaching in every school. London: Routledge.

Hobson, A. and Malderez, A. (2013) 'Judgementoring and other threats to realizing the potential of school-based mentoring in teacher education'. International Journal of Mentoring and Coaching in Education, 2 (2), 89-108.

Hobson, A., Malderez, A., Tracey, L., Homer, M., Ashby, P., Mitchell, N., Mclntyre, J., Cooper, D., Roper, T., Chambers, G. and Tomlinson, P. (2009) Becoming a Teacher: Teachers' experiences of initial teacher training, induction and early professional development. Final report. London: Department for Children, Schools and Families.

Hobson, A. and Mclntyre, J. (2013) 'Teacher fabrication as an impediment to professional learning and development: The external mentor antidote'. Oxford Review of Education, 39 (3), 345-65. 
Hodkinson, H. (2009) 'Improving schoolteachers' workplace learning'. In Gewirtz, S., Mahony, P., Hextall, I. and Cribb, A., Changing Teacher Professionalism: International trends, challenges, and ways forward. Abingdon: Routledge, 157-69.

Hordern, J. (2016) 'Regions and their relations: Sustaining authoritative professional knowledge'. Journal of Education and Work, 29 (4), 427-49.

Ingersoll, R. and Strong, M. (2011) 'The impact of induction and mentoring programs for beginning teachers: A critical review of the research'. Review of Education Research, 81 (2), 201-33.

Jones, K. (2011) 'Central, local and individual continuing professional development (CPD) priorities: Changing policies of CPD in Wales'. Professional Development in Education, 37 (5), 759-76.

Jones, M. (2009) 'Supporting the supporters of novice teachers: An analysis of mentors' needs from twelve European countries presented from an English perspective'. Research in Comparative and International Education, 4 (1), 4-21.

Killeavy, M. (2006) 'Induction: A collective endeavor of learning, teaching, and leading'. Theory Into Practice, 45 (2), 168-76.

Langdon, F.J. (2017) 'Learning to mentor: Unravelling routine practice to develop adaptive mentoring expertise'. Teacher Development, 21 (4), 528-46.

Langdon, F.J., Alexander, P.A., Dinsmore, D.L., and Ryde, A. (2012) 'Uncovering perceptions of the induction and mentoring experience: Developing a measure that works'. Teacher Development, 16 (3), 399-14.

Langdon, F.J., Alexander, P.A., Ryde, A., and Baggetta, P. (2014) 'A national survey of induction and mentoring: How it is perceived within communities of practice'. Teaching and Teacher Education, 44 (8), 92-105.

Langdon, F.J. and Ward, L. (2015) 'Educative mentoring: A way forward'. International Journal of Mentoring and Coaching in Education, 4 (4), 240-54.

Macbeath, J. (2012) Future of Teaching Profession. Brussels: Education International Research Institute.

Milton, E., Daly, C., Langdon, F., Palmer, M., Jones, K. and Davies, A. (forthcoming) 'Can schools really provide the learning environment that new teachers need? Complexities and implications for professional learning in Wales'.

National Assembly for Wales (2003) Statutory Instruments. 2003 No. 543. The Education (Induction Arrangements for School Teachers) (Wales) Regulations 2003. Cardiff: National Assembly for Wales. Online. https://tinyurl.com/y26l2t2r (accessed 23 July 2019).

National Assembly for Wales (2015) Inquiry into Supply Teaching. Cardiff: National Assembly for Wales.

New Zealand Education Council (2015) Guidelines for induction and mentoring and mentor teachers. Online. https://tinyurl.com/y287mwe4 (accessed 30 September 2018).

New Zealand Post Primary Teachers' Association (2016) Teachers in the precariat: Fixed-term contracts and the effect on establishing teachers (PPTA Annual Conference Papers). Wellington: New Zealand Post Primary Teachers' Association.

New Zealand Teachers Council (2010) Registered Teacher Criteria Handbook. Wellington: New Zealand Teachers Council.

New Zealand Teachers Council (2011) Guidelines for induction and mentoring programmes and for mentor teacher development in Aotearoa New Zealand. Wellington: New Zealand Teachers Council.

Norman, P.J., and S. Feiman-Nemser (2005) 'Mind activity in teaching and mentoring'. Teacher and Teacher Education, 21, 679-97.

O'Brien, J. and Jones, K. (2005) 'Politics, professionalism and pragmatics: Teacher professional development and learning - perspectives from Wales and Scotland'. Unpublished paper presented at the Australian Association for Research in Education conference, Parramatta, 29 November.

Organisation for Economic Co-Operation and Development (OECD) (2011) Teachers Matter: Attracting, developing and retaining effective teachers. Pointers for Policy Development. Paris: OECD. Online. www.oecd.org/education/school/48627229.pdf (accessed 28 September 2018).

Peiser, G., Ambrose, J., Burke, B. and Davenport, J. (2018) 'The role of the mentor in professional knowledge development across four professions'. International Journal of Mentoring and Coaching in Education, 7 (1), 2-18.

Reeves, J., Turner, E., Morris, B. and Forde, C. (2005) 'Changing their minds: The social dynamics of school leaders' learning', Cambridge Journal of Education 35(2), 253-74.

Stanulis, R. and Brondyk, S. (2013) 'Complexities involved in mentoring towards a high-leverage practice in the induction years'. Teachers College Record, 115 (10), 1-34. 
Sunde, E. and Ulvik, M. (2014) 'School leaders' views on mentoring and newly qualified teachers' needs'. Education Inquiry 5 (2), 285-99.

Sutcher, L., Darling-Hammond, L., and Carver-Thomas, D. (2016) A coming crisis in teaching? Teacher supply, demand, and shortages in the U.S.. Palo Alto, CA: Learning Policy Institute.

Talbot, D., Denny, J. and Henderson, S. (2018) '"Trying to decide ... what sort of teacher I wanted to be": Mentoring as a dialogic practice'. Teaching Education, 29 (1), 47-60.

Timperley, H., Wilson, A., Barrar, H., and Fung, I. (2008) Teacher professional learning and development: A best synthesis iteration. Wellington: Ministry of Education.

Welsh Government (2017a) Professional Standards for Teaching and Leadership. Cardiff: Welsh Government.

Welsh Government (2017b) Induction for newly-qualified teachers in Wales. Cardiff: Welsh Government.

Wenger, E. (1998) Communities of Practice: Learning, meaning and identity. Cambridge: Cambridge University Press.

Wenger, E. McDermott, A. and. Snyder, W. (2002). Cultivating Communities of Practice. Cambridge, MA: Harvard University Press. 